Original Contribution

\title{
A COMPARATIVE STUDY OF THE IMPLEMENTATION WIND FARMS INTEGRATION BASED ON MAXIMIZATION OF VOLTAGE STABILITY AND SYSTEM LOADABILITY
}

\author{
M. A. Kamarposhti ${ }^{*}$ \\ ${ }^{1}$ Department of Electrical Engineering, Jouybar Branch, Islamic Azad University, Jouybar, Iran
}

\begin{abstract}
This paper presents voltage stability in power systems which are connected to the wind farm generators. Two steady state models of wind generators, squirrel cage and doubly feed induction generators have been used. P-V curve that is used shows the maximum loading factor when the wind farm was installed. A modified IEEE 14 bus system has been selected to show the performance. For improvement of voltage stability, parallel FACTS devices are selected. Results show that STATCOM can improve the maximum loading factor of both wind generators better than SVC.
\end{abstract}

Key words: FACTS devices, voltage stability, squirrel cage induction generator, doubly fed induction generator

\section{INTRODUCTION}

In recent years wind energy which is a renewable energy has become very important in many countries. Wind power has features such as independence, randomness and being out of control. By increase of power in future wind farms, studying the impacts of very big accrete wind farms on power systems operation will be absolutely necessary [1]. Therefore, in order to analysis of the impacts of wind farms on the grid, an appropriate model should be used. Voltage instability and collapse problems usually take place in power systems which by consideration of heavy load and fault conditions can not realize the demand of reactive power. When wind farms are connected to a weak grid, voltage stability is one of the most important factors that have an impact on operation of wind farms. The usual types of wind turbines are those of constant speed that in them, turbine with induction generator directly connects to the grid. Connected induction generator for producing electricity absorbs reactive power from the grid. Then in order to maintain nominal voltage in a grid which is connected to a wind farm, reactive power compensation is needed [2].

Both SVC and STATCOM are important parallel devices of reactive compensation,

*Correspondence to: Mehrdad Ahmadi

Kamarposhti, Department of Electrical Engineering, Jouybar Branch, Islamic Azad University, Jouybar,

IRAN,E-mail:m.ahmadi@ jouybariau.ac.ir; ahmadi.k@gmail.com which are compared in voltage supporting, improving the transient stability and transmission limit, and damping low frequency oscillation. Simulation results in [3] are presented as high capacity static VAR system for SVC or STATCOM is placed on a transmission path on the power system. Firstly, single SVC and STATCOM are limited in voltage supporting after the fault occurrence, but STATCOM is little better than SVC. Secondly, STATCOM is much better than SVC in improving the transient stability and transmission limit. Thirdly, on the damping low frequency oscillation, STATCOM is much better than SVC as SVC and STATCOM have the same capacity, and performs similarly with SVC as the two have the same controllable capacity. Lastly, the results also indicate that dynamical response speed effects the control result little though STATCOM responses much faster than SVC.

In [4], the bifurcation analyses were made in a single-machine PQ dynamic-load system and a classical 3-node system. It is verified that both SVC and STATCOM compensation could effectively delay the occurrence of saddle-node bifurcation (SNB) in the two systems, and as greater as gains of the compensation devices are, the better the control effect to SNB point is; and STATCOM always plays better than SVC when concerned with the same value of their gains. In the 3-node system that can appear the Hopf bifurcations, SVC and STATCOM can effectively delay the unstable 
KAMARPOSHTI M. A.

Hopf bifurcation (UHB). When the gain values of SVC and STATCOM are the same and both of them are small, the control effect of SVC and STATCOM to UHB is almost the same; while both of the gain values are great, the control effect of STATCOM to UHB is apparently superior that of SVC. It can be demonstrated that the bifurcation control ability of STATCOM for voltage stability is more superior than that of SVC with a comprehensive consideration.

Reference [5] presented a new controller (called power system voltage stabilizer or PSVS) for dynamic voltage stability enhancement of power systems and/or prevention of fast voltage collapse. The PSVS is implemented through coordinated control of dynamic reactive sources. For implementation of a PSVS, the given power system is first divided into several small voltage control areas (VCAs) each of which include several loads and several dynamic reactive sources. Then for each VCA, a dynamic voltage stability index (DSVI) is defined that includes the voltage deviations of all load buses within the area. Finally, a coordinated control of all dynamic reactive sources of the area is used to improve the dynamic voltage index during voltage emergencies. The proposed method is applied for a modified IEEE 14-bus system and tested for severe voltage emergency. The simulation results obtained from PSS/E software package indicate significant improvement in dynamic voltage stability of the system.

Reference [6] analyzed the extent to which the low voltage ride through (LVRT) capability of wind farms using squirrel cage generators can be enhanced by the use of a STATCOM, compared to the thyristor controlled static var compensator (SVC). The transient stability margin is proposed as the indicator of LVRT capability. A simplified analytical approach based on torque-slip characteristics is first proposed to quantify the effect of the STATCOM and the SVC on the transient stability margin. Results from experiments with a STATCOM and a $7.5 \mathrm{~kW}$ induction machine emulating a wind turbine are used to validate the suggested analytical approach. Further verifications based on detailed time-domain simulations are also provided. Calculations, simulations and measurements confirm how the increased STATCOM rating can provide an increased transient stability margin and thus enhanced LVRT capability. Compared to the SVC, the STATCOM gives a larger contribution to the transient margin as indicated by both calculations and simulations. The inaccuracies introduced by neglecting the flux transients in the suggested approach are discussed and found reasonable for an estimation method when considering the simplicity compared to detailed time-domain simulation studies. A method for estimating the required rating of different compensation devices to ensure stability after a fault is suggested based on the same approach.

Also [7] studied system stability of wind farms based on fixed speed induction generators (FSIG) and investigates the use of SVC and STATCOM for wind farm integration. Due to the nature of asynchronous operation, system instability of wind farms based on FSIG is largely caused by the excessive reactive power absorption by FSIG after fault due to the large rotor slip gained during a fault. Wind farm models based on FSIG and equipped with either SVC or STATCOM are developed in PSCAD/EMTDC. It was found that the SVC and STATCOM considerably improve the system stability during and after disturbances, especially when the network is weak. Compared to SVC, STATCOM gave a much better dynamic performance, and provided a better reactive power support to the network, as its maximum reactive current output was virtually independent of the voltage at the point of common coupling (PCC).

References [8] considered the use of SVC and static STATCOM for wind farm integration. Wind farm models based on fixed speed induction generators (FSIG), using AC connection and equipped with either SVC or STATCOM, are developed. Stability problems with the FSIG are described. An investigation is conducted on the impact of STATCOM/SVC ratings and network strength on system stability after network faults, and comparison is also made between the performances of the two devices. It was found that the SVC and STATCOM considerably improve the system stability during and after disturbances, especially when the network is weak. It showed that the STATCOM gave a much better dynamic performance, and provided better reactive power support to the network, as its maximum reactive current output was virtually independent of the PCC voltage.

In [9], the voltage stability of the bus load in various static and dynamic load systems that are fed by a wind farm has been examined. In the control of load voltage and reactive power, 10 MVAr STATCOM and SVC is used. In the wind farm examined, Double Feed Induction Generator (DFIG) is used. In voltage and reactive power control, the results of time response and damping oscillation have been 
found using MATLAB/Simulink. The results achieved have proved that SVC and STATCOM yield good results when used in terms of voltage stability of the system.

This paper investigates and compares the implementation of two FACTS (Flexible AC Transmission System) devices to overcome the static voltage stability issue for a wind farm. Squirrel cage Induction Generator (SCIG) and Doubly Fed Induction Generator (DFIG) -based wind farm. The study includes the implementation of both STATCOM, and SVC as reactive power source at the point of common coupling to maintain a stable voltage. Two models of wind generator, based on the steady - state model are used. The P-V curve is used to express maximum load factor in power system when the wind farm was installed.

\section{VOLTAGE STABILITY DEFINITION AND CONCEPTS}

Voltage stability is defined as the power system's ability to maintain constant voltage in all buses after happening on a disturbance [10]. Voltage stability is a problem in power grids which depends on the intensity of load, fault and or to inadequate supply of reactive power. Although voltage stability is essentially a local phenomenon, but for utilizing of power system, controlling it would be essential. Increasing of load is the main cause of voltage instability, therefore voltage stability is called "load stability problem". Voltage collapse is a process which that developmental changes take place gradually in power a system which eventually leads to reactive power shortage and voltage reduction. This phenomenon can be seen by plotting receiving end voltage versus transmitted power diagram. This diagram is known as P-V curve, so that the voltage in receiving end decreases as transmitted power increases. In end of critical point, i.e. the point where any more increase in transmitting reactive power leads to a very quick reduction in voltage amplitude, before reaching to the critical point, large voltage drop caused by reactive power loss can be seen. The only way to maintain the system from voltage collapse is reducing load reactive power or increasing reactive power before reaching to the voltage drop point.

\section{Voltage Stability in a Two-Bus Power System}

Consider a Wind Farm connected to an infinite bus through a lossless transmission line as shown in Figure 1. The wind farm is injecting active $\left(\mathrm{P}_{\mathrm{WT}}\right)$ and reactive power $\left(\mathrm{Q}_{\mathrm{WT}}\right)$ at BUS 2 respectively. A single load, connected to BUS 2 , demands the active power $\left(\mathrm{P}_{\mathrm{D}}\right)$ and reactive power $\left(\mathrm{Q}_{\mathrm{D}}\right)$. For the sake of simplicity, the load is assumed to behave as impedance, in which consumed power from the load does not depend on frequency or on voltage variations in BUS 2 .

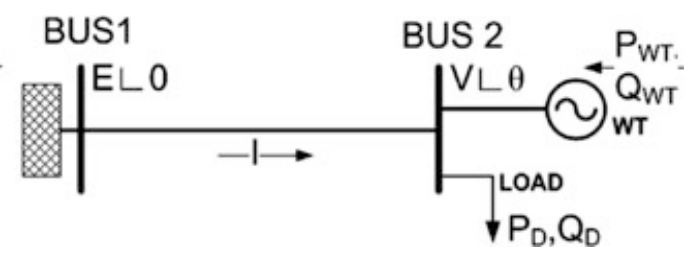

Figure 1. A single-two-bus system with a wind farm

The infinite bus (BUS 1) is represented as an ideal voltage source $\vec{E}$ in which voltage and frequency are constant. We assume three-phase and steady-state sinusoidal operating conditions, consequently, the phasor voltage source is $\vec{E}=E \angle 0$. Voltage instability could be produced when loads try to draw more power than the one able to be delivered by the transmission and by the generation system [11]. The more the load increases, the more the voltage on the load bus decreases until reaching a critical value that corresponds to the maximum power transfer. This maximum power transfer is related to voltage instability. Beyond this point voltage, stability is lost and voltage collapse could easily occur. From Figure 1, it can be proved:

$U=\sqrt{\frac{E^{2}}{2}-Q X \pm \sqrt{\frac{E^{4}}{4}-X^{2} P^{2}-X E^{2} Q}}$

If the wind farm is not operating, the active and reactive power injected by the wind farm are $\mathrm{P}_{\mathrm{WT}}=\mathrm{Q}_{\mathrm{WT}}=0$. In this situation active and reactive power in BUS 2 correspond only to the consumed power load, $\mathrm{P}=\mathrm{P}_{\mathrm{D}}$ and $\mathrm{Q}=\mathrm{Q}_{\mathrm{D}}$.

Consumed reactive power from the load depends on the active power and the load power factor by $Q=P \tan \varphi$. By means of this expression it is possible to obtain curves of load voltage just as a function of active power (PV) for various $\tan \varphi$. These curves are known as PV curves and they allow calculating the relationship between voltages and load in a specific region as soon as the load starts increasing. We can define the quantities and $\mathrm{U}_{\operatorname{maxP}}$ using the $\mathrm{PV}$ diagram (Figure 2). $\mathrm{P}_{\max }$ is the maximum deliverable power and $\mathrm{U}_{\max P}$ is the voltage in which this maximum happens.

This $\mathrm{P}_{\max }$ is often called the Point of Voltage Collapse (PoC) where the voltage drops rapidly with an increase of load. The risk of voltage instability can be measured by calculating the distance of the initial operating point (base case) to the Point of Voltage Collapse. This 
distance is called Voltage Stability Margin (VSM).

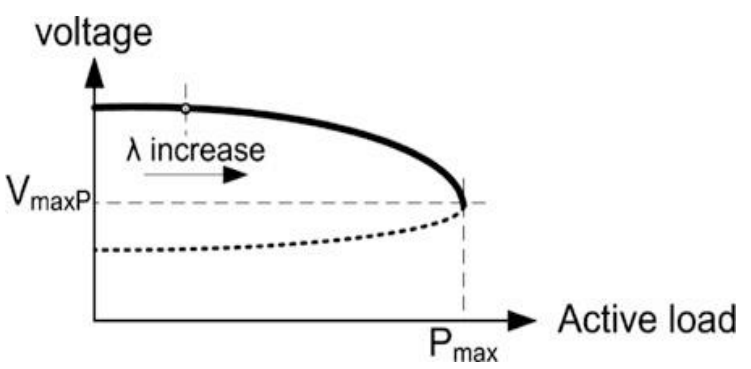

Figure 2. PV curves

\section{WIND FARM GENERATORS MODELING}

\section{Squirrel cage induction generator}

Squirrel cage induction generators (SCIG) are machines with constant speed that directly connect to the grid. Slip and rotor speed of a SCIG change in producing power, this change in rotor speed are very small so that they are assumed to be constant speed [12]. Nowadays they are widely used in wind turbine generators; however, their disability in producing reactive power is an imitative factor in using them. SCIG as a conventional PQ bus is modeled by generating real power and specific demand of reactive power. The reactive power demand can be represented as a function of bus voltage, as it is shown in below:

$$
\mathrm{Q} \approx \mathrm{V}^{2} \frac{X_{c}-X_{m}}{X_{c} X_{m}}+\frac{X}{V^{2}} P^{2}
$$

Where $\mathrm{Q}$ is generators consumable reactive power that can be calculated by having capacitance reactance $X_{c}$, magnetizing reactance $X_{m}$, total of rotor and stator reactance, terminal voltage $\mathrm{V}$ and generator real power $\mathrm{P}$. In this paper capacitor is more often considered to compensate the load of reactive power consumption.

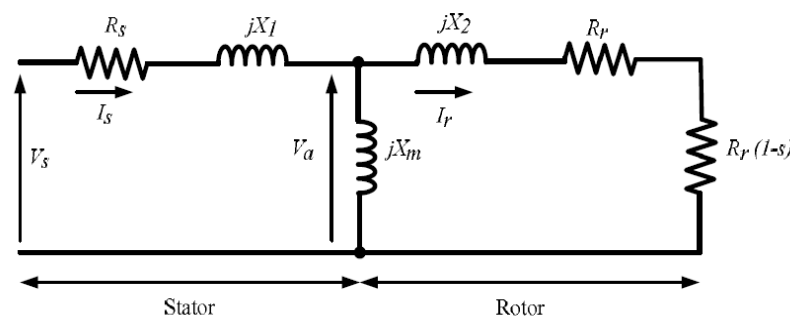

Figure 3. Equivalent model of SCIG

Figure 3 shows an equivalent circuit of a SCIG. Here $R_{s}$ is stator reactance, $X_{1}$ is stator reactance, $X_{2}$ is rotor reactance, $I_{s}$ is stator current, $I_{r}$ is rotor current, $V_{a}$ is the voltage drop on magnetizing reactance and $S$ is slip. According to the equivalent circuit, the relations (3) to (8) can be extracted:

$$
Z_{\text {in }}=R_{s}+j X_{1}+\left(j X_{m} \|\left(\frac{R_{r}}{S}+j X_{2}\right)\right)
$$

$$
\begin{aligned}
& I_{s}=\frac{V_{S}}{Z_{\text {in }}} \\
& I_{s}=\frac{V_{S}}{Z_{\text {in }}} \\
& V_{a}=V_{S}+I_{S}\left(R_{S}+j X_{1}\right) \\
& P=3\left|V_{S}\right|\left|I_{S}\right| \cos \theta \\
& Q=3\left|V_{S}\right|\left|I_{S}\right| \sin \theta
\end{aligned}
$$

Here $Z_{\text {in }}$ is incoming impedance and $Z_{r}$ is rotor impedance. The amount of incoming impedance depends on speed slip of wind turbine generator.

\section{Doubly fed induction generator}

Doubly fed induction generator (DFIG) is a variable speed machine that nowadays is very popular for application programs of wind turbine. The main cause for using them is their ability to change the operational speed in order to increase the optimum power drawn out from wind [13]. This has been done by supplying the rotor circuit with real power and a response from rotor converter. Converter circuit makes producing or consuming of reactive power possible, their structure is different from SCIG that only can consume reactive power.

Therefore DFIGs do not cause voltage instability problems that SCIGs do. DFIGs can be considered as PQ or PV bus in power flow studies and they can operate in both power factor or voltage control mode when a DFIG is modeled as a PQ bus, it is assumed that DFIG is operating in power factor control mode, i.e. determined reactive power is zero in the voltage control mode, DFIG can be represented as a PV bus with an applied Q constraint.

Figure 4 shows an equivalent circuit of DFIG with a voltage source. $V_{r}$ from rotor side is to control the output voltage of the generator. Equivalent circuit can express DFIG equations:

$$
\begin{aligned}
& V_{s}=R_{s} I_{s}+j X_{1} I_{s}+j X_{m}\left(I_{s}+I_{r}\right) \\
& \frac{V_{r}}{s}=\frac{R_{r}}{s} I_{r}+j X_{2} I_{r}+j X_{m}\left(I_{s}+I_{r}\right)
\end{aligned}
$$

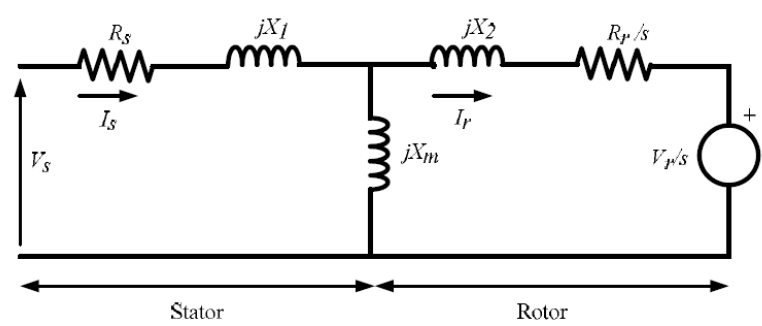

Figure 4. Equivalent model of DFIG

Active and reactive powers of generator are equal to total of power between stator and rotor side that can be defined by equations (11) to (13): 


$$
\begin{gathered}
P_{S}+j Q_{S}=3 V_{S} I_{S} \\
P_{r}+j Q_{r}=3 V_{r} I_{r} \\
P_{\text {total }}=P_{S}+P_{r}
\end{gathered}
$$

With the operation of rotor circuit in variable AC frequency, a unit can control the mechanical speed of machine. In this process, the net output power of machine is a combination of power which is attained from machine stator and rotor (through the converter) and it forwards to the system. When the machine is getting utilized in speeds higher than synchronous speed, the real power from the rotor is injected to the system through the converter. When the machine is getting utilized in speeds lower than synchronous speed, the real power from system and through the converter is absorbed by rotor. In synchronous speed, the voltage on the rotor is essentially a DC voltage and no considerable net power is transferred between rotor and system. The DFIG generator has the ability to prepare the same reactive power, for a standard synchronous machine.

\section{FACTS Devices Modeling}

The following general model is proposed for correct representation of SVC and STATCOM in voltage collapse studies [14]. The model includes a set of differential and algebraic equations of the form:

$$
\begin{aligned}
& x_{C}^{\bullet}=f_{C}\left(x_{C}, V, \theta, u\right) \\
& P=g_{p}\left(x_{C}, V, \theta\right) \\
& Q=g_{p}\left(x_{C}, V, \theta\right)
\end{aligned}
$$

Where $x_{C}$ represents the control system variables and the algebraic variables $V$ and $\theta$ denote the voltage magnitudes and phases at the buses to which the FACTS devices are connected. Finally, the variables $u$ represents the input control parameters, such as reference voltages or reference power owns. Description and terminal characteristics of these FACTS devices are given in the next subsections.

\section{SVC Model}

The two most popular configuration of this type of shunt controller are the fixed capacitor (FC) with a thyristor controlled reactor (TCR) and the thyristor switched capacitor (TSC) with TCR. Among these two setups, the second (TSC-TCR) minimizes stand-by losses; however from a steady-state point of view, this is equivalent to the FC-TCR. In this paper, the FC-TCR structure is used for analysis of SVC which is shown in Figure 5.

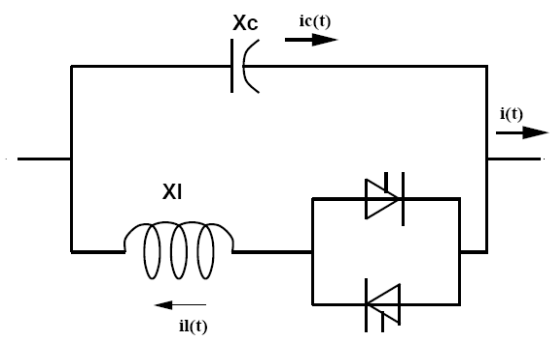

Figure 5. Equivalent FC-TCR circuit of SVC

The TCR consists of a fixed reactor of inductance $\mathrm{L}$ and a bi-directional thyristor valve that are fired symmetrically at an angle control range of $90^{\circ}$ to $180^{\circ}$, with respect to the SVC voltage.

Assuming controller voltage equal to the bus voltage and performing a Fourier series analysis of the inductor current waveform, the TCR at fundamental frequency can be considered to act like variable inductance given by $[15,16]$ :

$$
X_{V}=X_{L} \frac{\pi}{2(\pi-\alpha)+\sin 2 \alpha}
$$

Where, $X_{L}$ is the reactance caused by the fundamental frequency without thyristor control and $\alpha$ is the firing angle, hence, the total equivalent impedance of the controller can be represented as:

$$
X_{\ell}=X_{C} \frac{\pi / r_{x}}{\sin 2 \alpha-2 \alpha+\pi\left(2-1 / r_{x}\right)}
$$

Where $r_{x}=X_{C} / X_{L}$. The limits of the controller are given by the firing angle limits, which are fixed by design. The typical steady-state control law of a SVC used here is depicted in Figure 6, and may be represented by the following voltage-current characteristic:

$$
V=V_{\text {ref }}+X_{S L} I
$$

Where $V$ and $I$ stand for the total controller $R M S$ voltage and current magnitudes, respectively, and $V_{\text {ref }}$ represents a reference voltage.

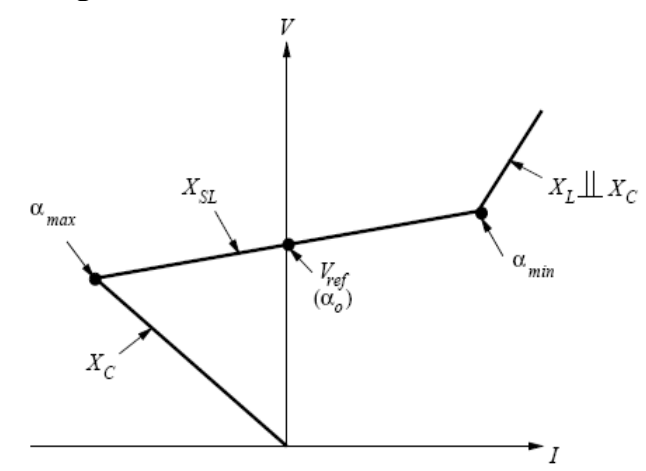

Figure 6. Typical steady state V-I characteristic of a SVC

Typical values for the slope $X_{S L}$ are in the range of 2 to $5 \%$, with respect to the SVC base; this is needed to avoid hitting limits for small variations of the bus voltage. 
A typical value for the controlled voltage range is $\pm 5 \%$ about $V_{\text {ref }}$ [15]. At the firing angle limits, the SVC is transformed into a fixed reactance.

\section{STATCOM Model}

STATCOM is the Voltage-Source Inverter (VSI), which converts a DC input voltage into AC output voltage in order to compensate the active and reactive power needed by the system [14]. Figures 7 and 8 show the Basic structure and typical steady state $\mathrm{V}-\mathrm{I}$ characteristic of STATCOM, respectively. From Figure 7, STATCOM is a shunt-connected device, which controls the voltage at the connected bus to the reference value by adjusting voltage and angle of internal voltage source. From Figure 8, STATCOM exhibits constant current characteristics when the voltage is low/high under/over the limit. This allows STATCOM to deliver constant reactive power at the limits compared to SVC.

The AC circuit is considered in steady-state, whereas the DC circuit is described by the following differential equation, in terms of the voltage $V_{d c}$ on the capacitor [17]:

$$
V_{d c}=\frac{P}{C V_{d c}}-\frac{V_{d c}}{R_{c} C}-\frac{R\left(P^{2}+Q^{2}\right)}{C V^{2} V_{d c}}
$$

The power injection at the $\mathrm{AC}$ bus has the form:

$$
\begin{gathered}
P=V^{2} G-K V_{d c} V G \cos (\theta-\alpha)-K V_{d c} V B \sin (\theta-\alpha) \\
Q=V^{2} B-K V_{d c} V B \cos (\theta-\alpha)-K V_{d c} V G \sin (\theta-\alpha)
\end{gathered}
$$

Where $k=\sqrt{3 / 8 m}$.

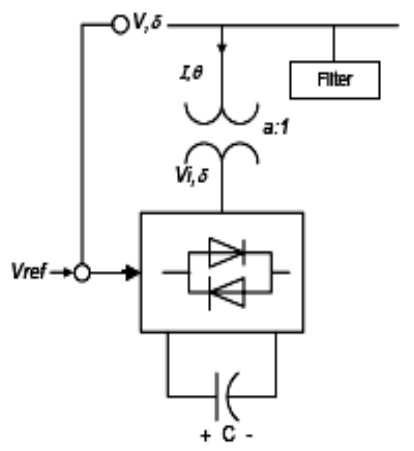

Figure 7. Basic structure of STACOM

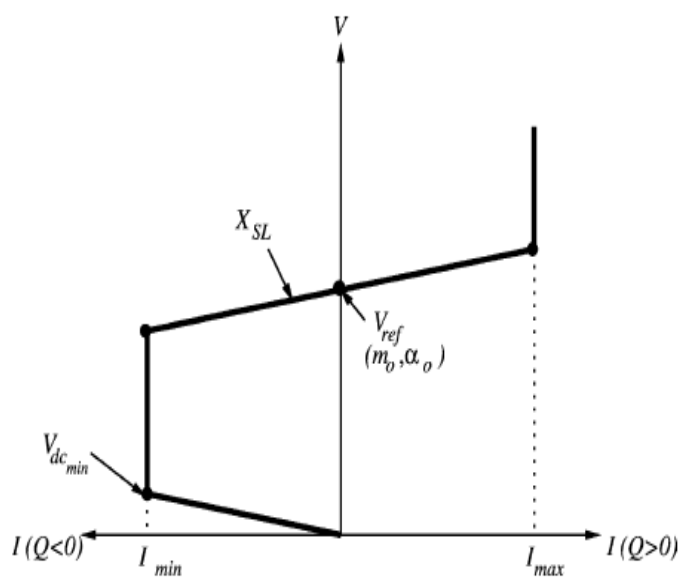

Figure 8. Typical steady state V-I characteristic of a STATCOM

\section{Simulation Results}

An IEEE 14-bus test system as shown in Figure 9 is used for voltage stability studies. The test system consists of five generators and eleven PQ bus (or load bus). The simulations use PSAT simulation software [18]. The behavior of the test system with and without Wind Farms and FACTS devices under different loading conditions is studied.

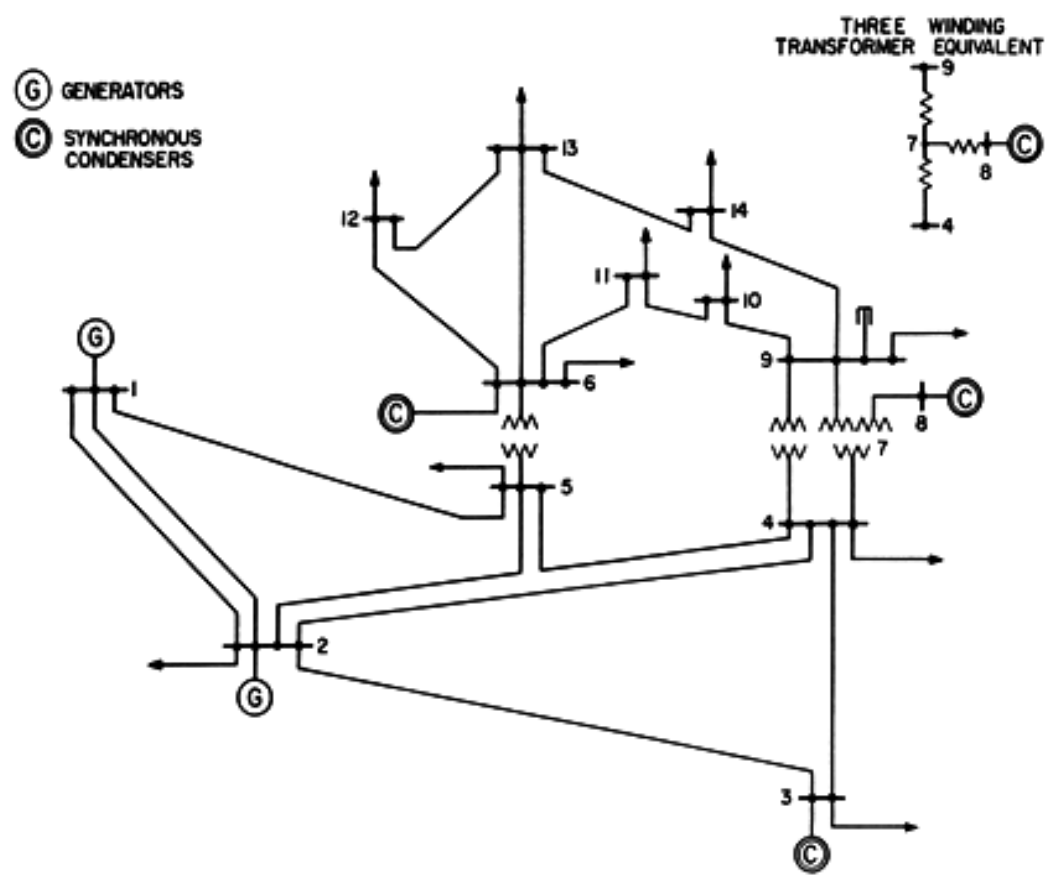

Figure 9. The modified IEEE 14-bus test system 
Voltage stability analysis is performed by starting from an initial stable operating point and then increasing the loads by a factor Error!

Bookmark not defined. to a singular point of power flow linearization is reached. The loads are defined as:

$$
\begin{aligned}
& P_{L}=P_{L 0}(1+\lambda) \\
& Q_{L}=Q_{L 0}(1+\lambda)
\end{aligned}
$$

Where $P_{L 0}$ and $Q_{L 0}$ are the active and reactive base loads, whereas $P_{L}$, and $Q_{L}$, are the active and reactive loads at bus $L$ for the current operating point as defined by $\lambda$.

From the continuation power flow results which are shown in the Figure 10, the buses 4,
KAMARPOSHTI M. A.

5, 9 and 14 are the critical buses. Among these buses, bus 5 has the weakest voltage profile. Voltage magnitude in MLP in bus 14 that is known as the weak bus is 0.6865 p.u. Figure 11 shows PV curves for IEEE 14-bus test system. The system presents a collapse or Maximum Loading Point, where the system Jacobian matrix become singular at $\lambda_{\max }=2.7119$ p.u.

Also Figure 12 show reactive power profile for IEEE14 bus system. Based on largest entries in the right and left eigenvectors associated to the zero eigenvalue at the collapse point, bus 14 is indicated as the "critical voltage bus" needing voltage and power support. Based on collapse analysis bus 14 is targeted as the first location for installation of a wind farm.

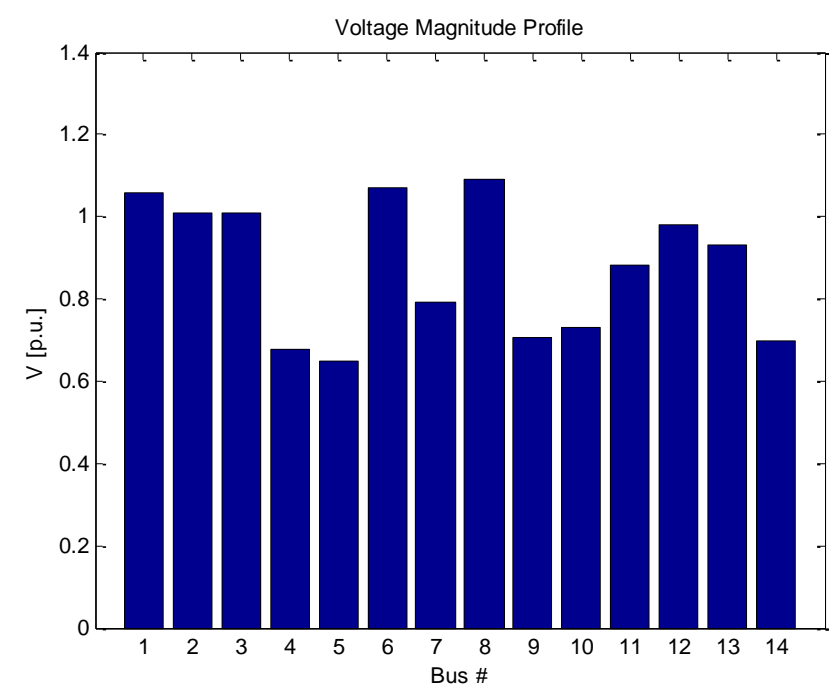

Figure 10. Voltage magnitude profile for IEEE 14-bus test system

Wind farms connected to the selected bus in the IEEE 14-bus system. The wind farm includes 43 wind turbine generators with a total capacity of $43 \mathrm{MW}$. The understudy wind farm is connected to bus 14 through a transmission line with a line impedance of $5.25 \times 10^{-7}+\mathrm{j} 1 \times 10^{-6}$ p.u. and a transformer with a capacity of 100 MVA.

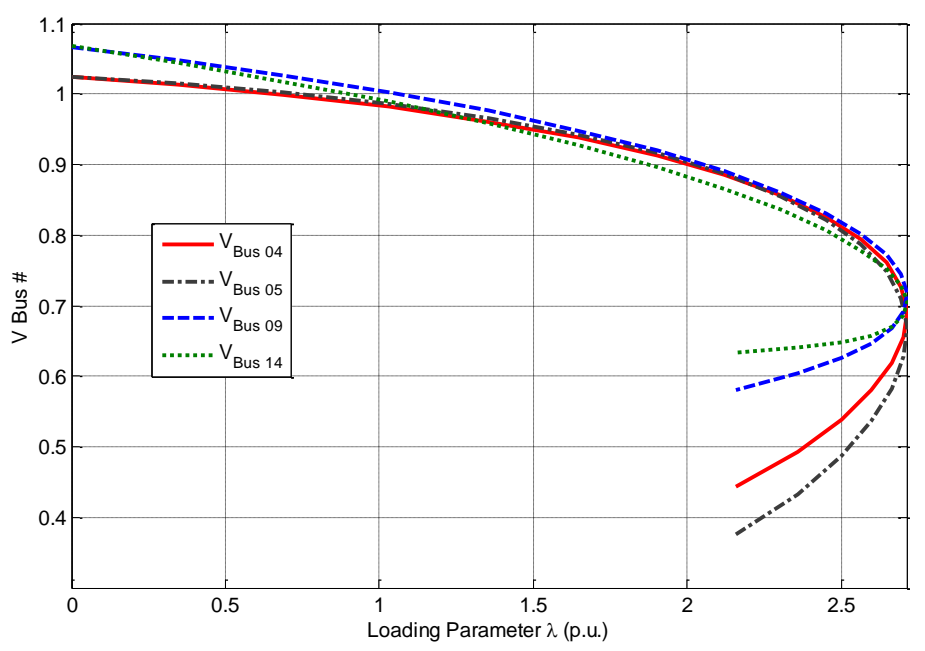

Figure 11. PV curves for IEEE 14-bus test system 


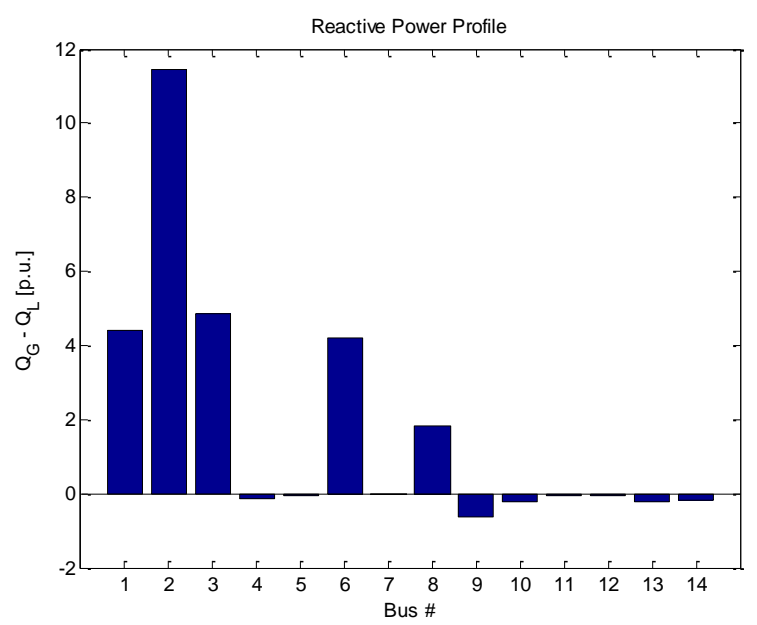

KAMARPOSHTI M. A.

Figure 12. Reactive power profile for IEEE14 bus system

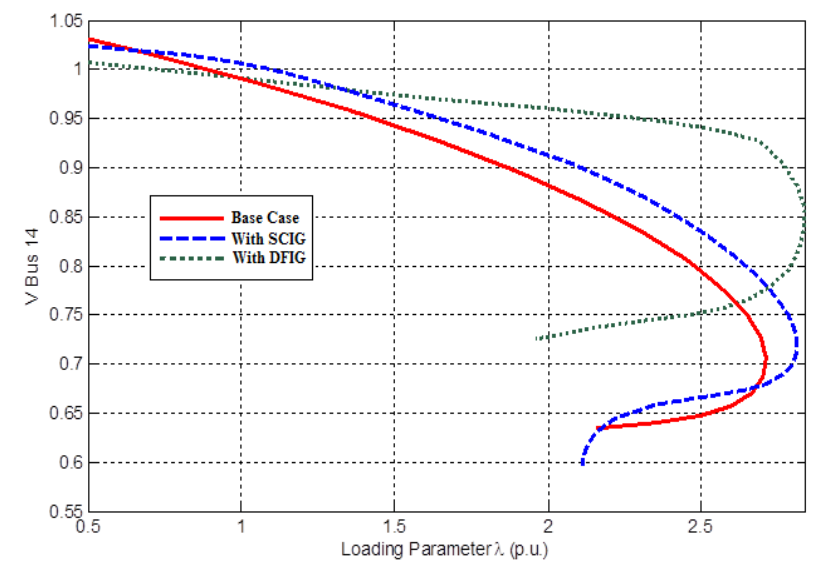

Figure 13. PV curves for 14-bus test system with and without wind farm at bus 14

The iteration analysis method is also used to find the position at the PQ bus with $17 \mathrm{~m} / \mathrm{s}$ wind speed. Figure 13 shows P-V curve when connected SCIG and DFIG at bus 14. The maximum load factor with wind farms is increased. It is shown in Table $\mathbf{1}$ that if wind farm based SCIG connect to bus 14, it has maximum load factor equal to $2.813 \mathrm{p.u}$. at a wind speed of $15 \mathrm{~m} / \mathrm{s}$ but when the wind speed is $25 \mathrm{~m} / \mathrm{s}$, the maximum load margin reduces because the generator absorbs reactive power from the power system.

Table 1. The relation between wind speed and maximum load factor and bus position with SCIG

\begin{tabular}{|c|c|c|c|}
\hline $\begin{array}{c}\text { Wind } \\
\text { Speed } \\
(\mathrm{m} / \mathrm{s}) \\
\text { Location }\end{array}$ & 5 & 15 & 25 \\
\hline Bus 4 & 2.7201 & 2.7719 & 2.7201 \\
\hline Bus 5 & 2.7182 & 2.7588 & 2.7182 \\
\hline Bus 9 & 2.7081 & 2.7947 & 2.7081 \\
\hline Bus 10 & 2.7065 & 2.7959 & 2.7065 \\
\hline Bus 13 & 2.6993 & 2.7864 & 2.6993 \\
\hline Bus 14 & 2.7072 & 2.813 & 2.7072 \\
\hline
\end{tabular}

Also, it is calculated that if wind farm based DFIG connect to bus 14 , it has maximum load factor equal to 2.838 p.u. In order to maintain the stable operation of wind turbine generators, this paper presents some of control strategies by using FACTS devices to improve stability margin. SVC and STATCOM are as reactive power control devices for wind farms connected to the power system. Theses devices also can control the voltage in a load bus.

Table 2 shows the results of installation SVC and STACOM at bus 9 on maximum load factor $\left(\lambda_{\max }\right)$ and Mega Watt Margin (MWM) for modified 14-bus test system. Figures 14 and 15 show comparison of maximum load 
factor and Mega Watt Margin and with various FACTS devices respectively. From the table and figures, it is obvious that STATCOM can improve the maximum loading
KAMARPOSHTI M. A. factor better than SVC for both types of wind farm generators. It can be observed that the improvement of voltage in bus 14 with STATCOM is more than the case that SVC inserted in the system.

Table 2. Results of installation SVC and STACOM

\begin{tabular}{|c|c|c|c|c|c|c|}
\hline \multirow{2}{*}{} & \multicolumn{2}{|c|}{ Base Case } & \multicolumn{2}{c|}{ With SCIG } & \multicolumn{2}{c|}{ With DFIG } \\
\cline { 2 - 7 } & $\lambda_{\max }$ & MWM & $\lambda_{\max }$ & MWM & $\lambda_{\max }$ & MWM \\
\hline $\begin{array}{c}\text { Without } \\
\text { FACTS }\end{array}$ & 2.7119 & 6.1998 & 2.813 & 6.5738 & 2.8381 & 6.6651 \\
\hline SVC & 2.7963 & 6.4882 & 2.8837 & 6.8302 & 2.9252 & 6.9806 \\
\hline STATCOM & 2.8883 & 6.847 & 2.9604 & 7.1085 & 2.9493 & 7.0683 \\
\hline
\end{tabular}

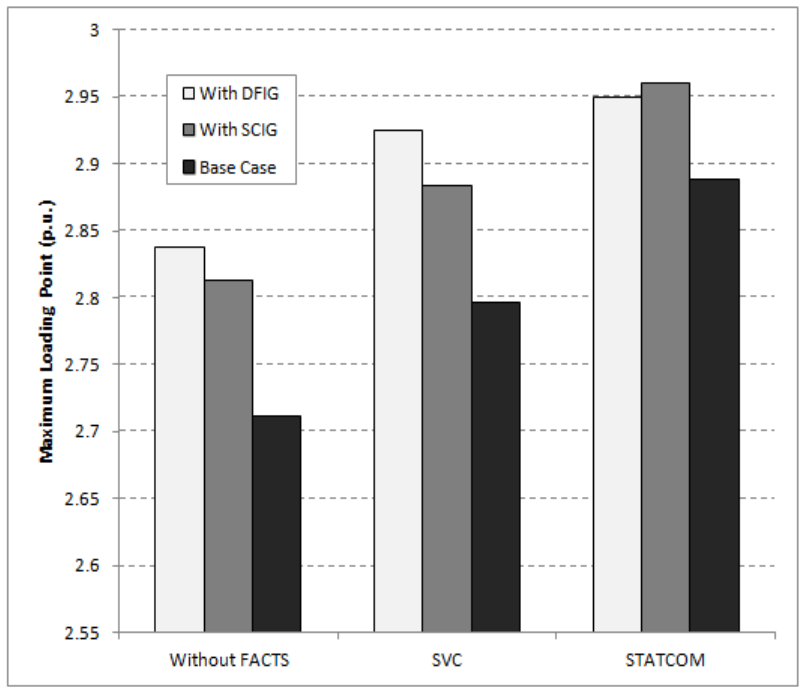

Figure 14. Comparison of Maximum Loading Point with various FACTS devices

Figures 16 and 17 show comparison of PV curves for modified 14-bus test system with and without FACTS devices on bus 14 in presence of SCIG and DFIG respectively. It indicates that with the application of SVC and STATCOM, voltage profile in bus 14 has improved significantly. It is obviously from
Figures that the MLP of the system with STATCOM is highest, while that without FACTS is lowest. Voltage reduction is lowest in the case of STATCOM. It is obvious that STATCOM gives the more maximum loading margin compared to SVC.

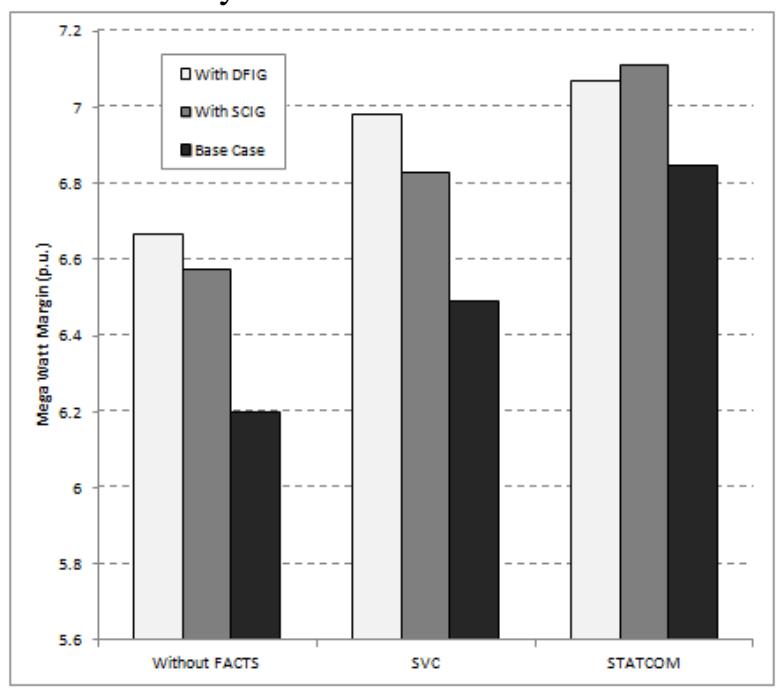

Figure 15. Comparison of Mega Watt Margin with various FACTS devices 
Notice with SVC, STATCOM keeps all busses within the acceptable voltage range. Using of SVC and STATCOM give the view of voltage decline before entering to the collapse point.
KAMARPOSHTI M. A.

The SVC and STATCOM significantly affects PV curves, which improves the critical point without masking the nose point by only shift out PV curve.

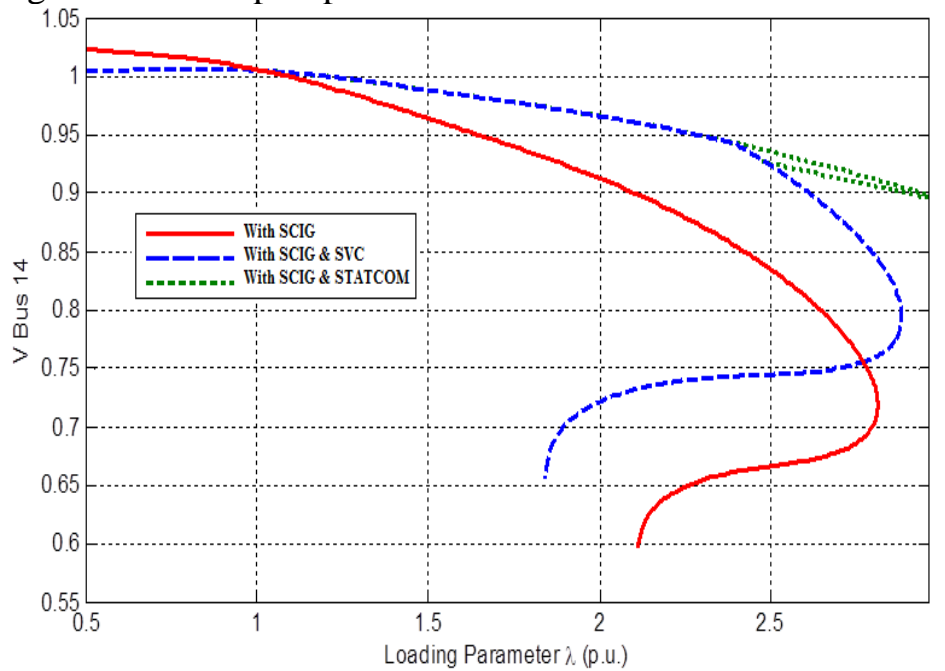

Figure 16. PV curves for modified 14-bus test system with and without FACTS devices at bus 14 in presence of SCIG

The results of simulations on the IEEE 14 bus test system have clearly shown that how SVC and STATCOM devices increased the buses voltage, power limits, line powers, and loading capability of the network. The results of simulations also show that with the insertion of STATCOM, improving these parameters and steady-state stability of the system is more than the case when the SVC is inserted in the system.

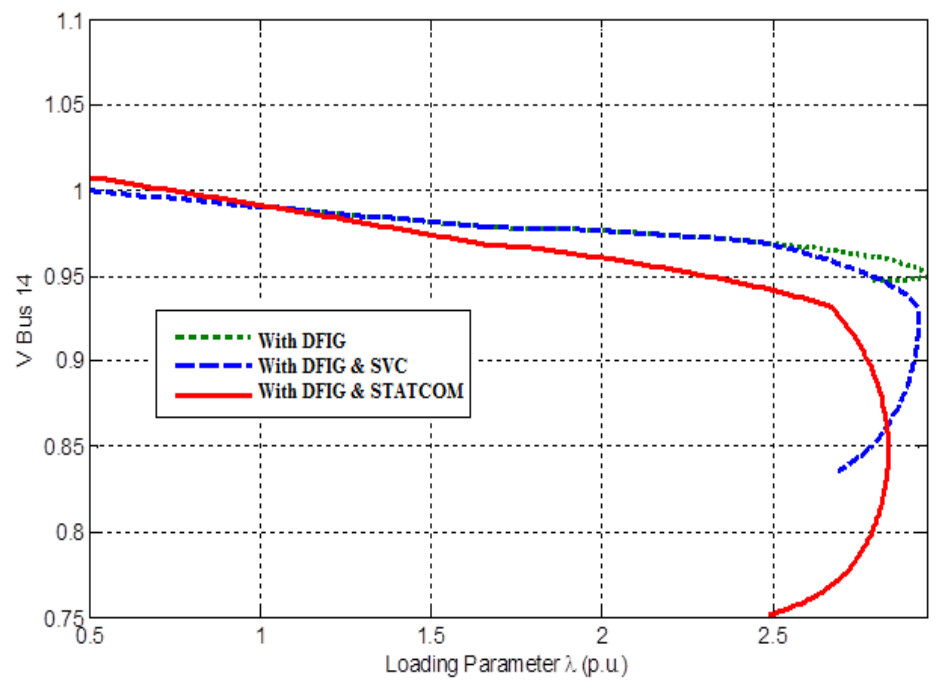

Figure 17. PV curves for modified 14-bus test system with and without FACTS devices on bus 14 in presence of DFIG

\section{CONCLUSION}

The steady state impact of constant speed and variable speed wind turbine generators on voltage stability margin was studied in this paper. FACTS devices were selected for voltage stability improvement. Results show that STATCOM can improve the maximum loading factor better than SVC for both types of wind farm generators. Also results obtained from simulations show that in presence of FACTS devices, static loading limit and voltage level in buses of mentioned grid increases. Also, this method can present a direct advantage in studying of the impact of wind turbine generator installation on voltage stability for the factory that manufactures the realizing power system.

\section{REFERENCES}

1. Kundur, P.; Paserba, J.; Ajjarapu, V.; Andersson, G.; Bose, A.; Canizares, C.; Hatziargyriou, N.; Hill, D.; Stankovic, A.; Taylor, C.; Van Cutsem, T.; Vittal, V., IEEE/CIGRE Joint Task Force on Stability and Definition, Definition and Classification of Power Stability, IEEE Transactions on power system, Vol.19, No.3, pp.1387-1401, May 2004. 
KAMARPOSHTI M. A.

2. G.Coath, M.Al-Dabbagh, Effect of steadystate wind turbine generator model on power flow convergence and voltage stability limit, Australasian universitie power engineering conference (AuPEC 2005), Australia , 2005.

3. Ding Lijie; Liu Yang; Miao Yiqun, Comparison of High Capacity SVC and STATCOM in Real Power Grid, International Conference on Intelligent Computation Technology and Automation (ICICTA), Vol. 1, pp. 993-997, 2010.

4. Sheng Li; Qi Zhao; Cheng Chen; Yan Xu, A comparative study on voltage stability bifurcation control ability of SVC and STATCOM, China International Conference on Electricity Distribution (CICED), pp. 1-4, 2012.

5. Radman, G. ; Pama, A. ; Powell, J. ; Gao, D. Dynamic Voltage Stability Improvement using coordinated control of dynamic VARsources, Bulk Power System Dynamics and Control - VII. iREP Symposium Revitalizing Operational Reliability, pp. 1-6, 2007.

6. Molinas, M.; Suul, J.A.; Undeland, T., Low Voltage Ride Through of Wind Farms With Cage Generators: STATCOM Versus SVC, IEEE Transactions on Power Electronics, Vol. 23, No. 3, pp. 1104-1117, 2008.

7. Lie Xu ; Liangzhong Yao ; Sasse, Christian, Comparison of Using SVC and STATCOM for Wind Farm Integration, International Conference on Power System Technology (PowerCon), pp. 1-7, 2006.

8. Foster, S. ; Xu, L. ; Fox, B., Grid Integration of Wind Farms Using SVC and STATCOM, Proceedings of the 41st International Universities Power Engineering Conference, Vol. 1, pp. 157-161, 2006.

9. Ozturk, A.; Dosoglu, K., Investigation of the control voltage and reactive power in wind farm load bus by statcom and SVC, International Conference on Electrical and Electronics Engineering, ELECO, pp. I-60I-64, 2009.
10.N. Mithulananthan, A.Sode-Yome, N.Acharya, S.Phi- chaisawat, Application of FACTS Controllers in Thailand Power Systems, RTG Budget-Joint Research Project, January 2005.

11.Cutsem TV, Vournas C, Voltage stability of electric power systems. Kluwer, Boston. ISBN 0792381394, 1998.

12.A.Sode-Yome, N. Mithulananthan, K.Y.Lee, A Maximum Loading Margin Method for Static Voltage Stability in Power System, IEEE Transaction on Power Systems, Vol.21 No.2, May 2006.

13.A. Sode-Yome, N. Mithulananthan, Comparison of shunt capacitor, SVC and STATCOM in static voltage stability margin enhancement, International Journal of Electrical Engineering Education, UMIST, Vol. 41, No.3, 2004.

14.C. A. Canizares, Power Row and Transient Stability Models of FACTS controllers for Voltage and Angle Stability Studies, IEEE/PES WM Panel on Modeling, Simulation and Applications of FACTS Controllers in Angle and Voltage Stability Studies, Singapore, Jan. 2000.

15.C. A. Canlzares, Z. T. Faur, Analysis SVC and TCSC Controllers in Voltage Collapse, IEEE Trans. Power Systems, Vol. 14, No. 1, February 1999, pp. 158-165.

16.N. Talebi, M. Ehsan, S.M.T Bathaee, Effects of SVC and TCSC Control Strategies on Static Voltage Collapse Phenomena, IEEE Proceedings, SoutheastCon, pp. 161 - 168, Mar 2004.

17.A. Kazemi, V. Vahidinasab and A. Mosallanejad, Study of STATCOM and UPFC Controllers for Voltage Stability Evaluated by Saddle-Node Bifurcation Analysis, First International Power and Energy Conference PECon/IEEE, Putrajaya, Malaysia, November 28-29, 2006.

18. F. Milano, Power System Analysis Toolbox, Version 2.1.8, Software and Documentation, 2013. 
KAMARPOSHTI M. A. 